\title{
PRECANCEROUS AND CANCEROUS LESIONS OF CERVIX DIAGNOSED BY PAP'S SMEAR - A HOSPITAL BASED STUDY
}

\author{
Komal Singh Likhar¹, Ajit Saluja², Santosh G. Gupta3 ${ }^{3}$ R. A. Hazari, S. K. Likhar ${ }^{5}$
}

HOW TO CITE THIS ARTICLE:

Komal Singh Likhar, Ajit Saluja, Santosh G. Gupta, R. A. Hazari, S. K. Likhar. "Precancerous And Cancerous Lesions of Cervix Diagnosed by Pap's Smear-A Hospital Based Study". Journal of Evolution of Medical and Dental Sciences 2014; Vol. 3, Issue 08, February 24; Page: 1899-1904, DOI: 10.14260/jemds/2014/2076

\begin{abstract}
BACKGROUND: Cervical intra-epithelial neoplasia (CIN) and cervical cancer remain important health problems for women worldwide. It is largely a preventable disease that is characterized by a long lead time. The objective of this study was to determine the frequency of precancerous lesions of cervix by Pap smear screening. METHODS: A retrospective hospital based study was conducted at Department of Pathology, in a Tertiary Care Institute and associated hospital, Bhopal. Data was collected from the records of Pap's smear testing done on 388 patients in years 2011 \& 2012. Analysis was done by entering data in SPSS software and Chi-square test was applied to find statistical significance. RESULTS: Most common lesions on Pap's smear was Low grade squamous intraepithelial lesion (LSIL) in 104 (26.8\%) of cases and High grade squamous intraepithelial lesion (HSIL) in $15(3.9 \%)$ of cases. 44 (11.3\%) were senile Atopic Changes, parasitic Infection in 27 (7\%) of cases and $2(0.5 \%)$ were carcinoma cervix cases. All the cervical lesions were most common in age of 31-40 yrs. and were significantly associated with age. CONCLUSIONS: Pap's smear examination information should be spread in community apart from hospitals. Especially the young women should be motivated for regular Pap's smear. Pap's smear is the single most important screening method for early detection of precancerous \& cancerous cervical lesions.
\end{abstract}

KEYWORDS: Pap's smear, precancerous lesions, cancerous lesions.

INTRODUCTION: Cervical cancer is one of the most common cancers in women, with an estimate of 468,000 new cases annually in the world, $80 \%$ of these cases occurring in developing and undeveloped countries. ${ }^{1}$ India accounts for one-fifth of the world burden of cervical cancer. ${ }^{2}$ The incidence of cervical cancer has declined in western countries following the introduction of screening programs which are often rudimentary or non-existent in countries like India due to infrastructural, financial and personnel constraints. ${ }^{3}$ In developing countries like ours, more than three fourths of cervical cancer patients are diagnosed at advanced stages leading to poor prospects of long-term survival and cure. ${ }^{4}$

Almost $20 \%$ to $60 \%$ of all cervical cancer deaths could be avoided by improving screening programs. ${ }^{5}$ "Protection against cervical cancer may involve repeated screening over a lifetime. Current guidelines indicate that all sexually active women and/or those who have reached 18 years of age should undergo an annual Pap-smear test. ${ }^{6}$ after a woman has three or more consecutive, negative examinations, the Pap test may be performed less frequently at the discretion of her physician"

The Papanicolaou (Pap) test is a screening test performed using cells from the uterine cervix. The Pap test was introduced as a cervical screening test in 1943 by George Papanicolaou for whom it is named. The test is simple, quick, and painless. With the woman lying on an examination table, the 
clinician inserts a speculum into her vagina to open it and then, using a wooden scraper, takes a sample of cells from in and around the cervix; this is placed on a glass slide and rinsed in liquid fixative and sent to the laboratory for examination. The Papanicolaou cervical cytology test is capable of detecting cervical cancer at an early stage and is used widely in developed countries, where it has decreased both the incidence and mortality of cervical cancer. It has been estimated that the use of this simple and cost-effective technique has reduced the incidence of cervical cancer by at least 70\%. Unfortunately, many developing countries lack the facility to carry out widespread Pap screening. ${ }^{7-9}$

A critical way to prevent cervical cancer is to have Pap tests to detect cervical cell changes. Cervical cancer is more common in women who do not have Pap test regularly. Half of women diagnosed with cervical cancer are between 35 to 50 years old. Secondary prevention, achieved through Pap smear testing, is the single most effective tool in reducing deaths due to cervical cancer. ${ }^{10}$

To date the cervical cancer prevention effort worldwide have focused on screening sexually active women using cytology smear and treating precancerous lesion thus by decreasing the incidence and mortality from cervical cancer. The diagnosis is made by screening an asymptomatic population, the test in use are cervical cytology, and histological examination of the biopsy material added by numerous technique such as Cervicography and assessment of HPV DNA type. In most developed countries, women are advised to have their first test soon after becoming sexually active and subsequently every 1-5 years. ${ }^{11}$ The current recommendation of the American Cancer Society, National Cancer Institute, American College of Obstetrics \& Gynaecologists and others is that all women who are sexually active above the age of 18 years should have annual Pap's smear for 3 years. If the women have 3 consecutive negative Pap's smear, the physicians may consider extending the interval of 3-5 years. ${ }^{12}$

With this background the present study is being planned to find the Precancerous \& Cancerous lesions of cervix in women as diagnosed by Pap smear in a hospital based population.

MATERIAL \& METHODS: A retrospective hospital based study was conducted at Department of Pathology, Tertiary Care Institute and associated hospital, Bhopal. Data was collected from the records of Pap's smear done on 388 patients in last two years duration from 2011 to 2012. Inclusion criteria were Pap's smear done on out-patient \& in-patient basis in cytology section. An exclusion criterion was all Pap's smears reported as inflammatory and with reactive changes. Pap's smear results were then entered in SPSS software and analysis was done. Chi-square test was applied to find statistical significance.

CYTOLOGIC TESTS: The conventional Pap smear test was used for cytology. The Pap smear has been the method of choice for cervical cancer screening since the 1950s, proving valuable for mass screening and enabling detection of lesions early enough for effective treatment. The Pap smear has limitations, most important is its limited sensitivity and the subjective interpretation of the results. On the other hand, wide acceptance, meeting most of the criteria for a good screening test in settings with adequate resources are strengths of Pap smear testing.

Pap smear was taken with a disposable wooden spatula. Scrapings from squamo-columnar junction of cervix, were spread on a glass slide and dipped in methanol spirit container. The sample was sent to pathology department of hospital for cytological examination. The slides were stained 
with Papanicolaou stain, screened and reported by a consultant pathologist. The result of cervical smear was reported as normal, inadequate smear, LSIL and HSIL etc. Evaluation of the cervical cells was done using the Bethesda System 2001.12

RESULTS: Out of total 388 pap's smear, normal Pap's smear was found in 78 (20.1\%) of cases, repeat Pap's smear was advised in 40 (10.3\%) of cases and inadequate smear was found in 78 (20.1\%). Most common lesions on Pap's smear was LSIL (Mild dysplasia) in 104 (26.8\%), HSIL (Moderate \& severe dysplasia) in 15 (3.9\%), senile Atopic Changes in $44(2.4 \%)$ and $2(0.5 \%)$ were carcinoma cervix cases.

Dysplastic cervical lesions like LSIL found in 30 (28.8\%) was most common in 31-40 yrs. age followed by 27 (26.0\%) in 41-50 yrs. age. HSIL found in 07 (46.7\%) was most common in 41 - 50 yrs. age followed by 4 (26.7\%) in 61-70 yrs. age. Senile Atrophic Changes were most common above 40 yrs. age with maximum i.e.13 (29.5\%) at 41-50 yrs. \& $12(27.3 \%)$ at 51-60 yrs. age and $10(22.7 \%)$ above 70 yrs. age.

All the cervical lesions were most common in 31-40 yrs. age, 103 cases (26.5\%) while least common in above 70 years of age, 24 (6.2\%). All cervical lesions diagnosed by Pap's smear were found to be significantly associated with age of women with p value $<0.0001$.

DISCUSSION: In a study by Sania Tanveer on 300 patients attending OPD, cervical intra-epithelial neoplasia (CIN) was seen in $2.6 \%$ of patients; $38 \%$ were below the age of 20 years and $62 \%$ above the age of 20 in their study. ${ }^{13}$ Dysplastic lesions were found in $1.76 \%$ cases among which $1.60 \%$ was CIN I and II and $0.6 \%$ CIN III. Carcinoma in situ (CIS) was seen in $0.3 \%$ and frankly invasive adenocarcinoma in $0.6 \%$ patients. In our study also we found the similar findings.

In a prospective study by Shrivastava M on 680 Pap's smear samples, 55 were unsatisfactory for reporting, 509 (81.44\%) were NILM (Negative for Intraepithelial Lesion or Malignancy) and 116 (18.56\%) with epithelial cell abnormality. ${ }^{14}$ Out of 116 (18.56\%) samples with epithelial cell abnormality, 31 (4.96\%) smears were ASCUS (Atypical Squamous Cells of Undetermined Significance), AGUS in 7 (1.12\%), LSIL in 46 (7.36\%),HSIL in $22(3.52 \%)$ and squamous cell carcinoma (SCC) in 10 (1.6\%) samples. The proportion of LSIL cases is very low as compared to our study.

In a retrospective study by Ranabhat SK on 880 cervical Pap smears in Pathology Dept. from June 2009 to Nov. 2010 reported HSIL as the most common with 6 cases (40\%), followed by LSIL in 3 cases (20\%), then Atypical Squamous Epithelial Cells of Undetermined Significance, and atypical Glandular Cells and Squamous cell carcinoma with 2 cases each (13.3\%). Eighty percent of all the abnormal epithelial lesions were found in women above the age of 40 years. ${ }^{15}$ In our study we also found dysplastic lesions in women more than 40 yrs. of age.

In a study by Bukhari MH done on 1000 Pap smears from Jan 2007 to June 2009 included only cases with neoplastic cytology. The normal 50\%, inadequate $1.8 \%$, neoplastic $10.2 \%$, and infective smears $38.3 \%$, were reported in their study. ${ }^{16}$ Of the 102 cases with neoplastic lesions $46(45 \%)$ had LSILs, 22 (21.5\%) had HSILs, 14 (13.7\%) had squamous cell carcinoma, and 6 (5.8\%) were adenocarcinoma. Ten $(9.8 \%)$ cases showed atypical squamous cells of undetermined significance (ASCUS) and four (3.9\%) cases had atypical glandular cells of undetermined significance (AGUS). In our study we found comparatively higher proportion of neoplastic lesions. 
In a study by Bal MS on 300 Pap's smears from OPD of Obs/Gynec, 15 cases were positive for malignancy, 273 were negative, and 12 smears were inadequate. Epithelial cell abnormalities were found in $5 \%$ of smears, ASUS in $0.3 \%$, SIL in $3.4 \%$ which includes LSIL $2.7 \%$ and HSIL $0.7 \%$. Invasive carcinoma was seen in $1.3 \%$ cases 17 In our study we found higher proportion of LSIL \& HSIL cases.

Strength \& Limitations of study: This study was a two year review of data from a hospital, it well describes the Precancerous \& Cancerous lesions in cervix and Pap' smear as an important screening method. Limitation of this study was histopathology data was not available for cases reported as LSIL \& HSIL on Pap's smear. Other studies may be planned out to know about the benefits of regular Pap's smear follow up at younger age group for detection of Precancerous lesions in uterine cervix.

CONCLUSION: Finally to conclude in the present study most common lesions on Pap's smear was LSIL (Mild dysplasia) found in 104 (26.8\%) of cases while HSIL (Moderate \& severe dysplasia) was found in $15(3.9 \%)$ of cases. $2(0.5 \%)$ were carcinoma cervix cases and $44(2.4 \%)$ were of senile Atopic Changes.

Although cervical carcinoma does not develop suddenly from normal epithelium but is presented by a precancerous lesions like LSIL \& HSIL which needs to be detected at the earliest. Pap's smear is the most important screening method for detection of precancerous cervical lesions. So widespread information on utility of Pap's smear should be spread in the community.

\section{BIBLIOGRAPHY:}

1. Standard \& Guidelines, Cervical and breast cancer screening by VIA \& CBE. New York: The United Nations Population Fund; 2006.

2. Desai M. An assessment of community based cancer screening program among Indian women using the Anganwadi workers. J Obstet Gynecol Ind. 2004; 54: 483- 487.

3. Adeleke NA, Komolafe JA. Knowledge, attitude and practice of cervical cancer screening among women of reproductive age group in Osogbo, south western Nigeria. Sex Health Matters. 2007; 8: 70-73.

4. Postgraduate Institute of Medical Education and Research. Guidelines for cervical cancer screening programme. Government of India-WHO Collaborative Programme (2004-2005) Chandigarh, India: PGIMER; 2006.

5. Watkins MM, Gabali C, Winkleby M, Gaona E, Lebaron S. Barriers to cervical cancer screening in rural Mexico. Int Gynecol Cancer. 2002; 12(5):475-479.

6. Fernandez-Esquer ME, Espinozal P, Ramirez AG, McAlister AL. Repeated Pap smear screening among Mexican-American women. Health Educ Res. 2003; 18(4): 477-487.

7. Yousaf A, Yousaf NW. Review of cervical intra epithelial neoplasia (CIN) latest concepts of screening and management protocol. Pak J Obstet Gynaecol.1992; 5:23-5.

8. Singh P, Ilancheran A. The 'Pap' or cervical smear and the role of colposcopy in screening for carcinoma of the cervix. Singapore Med J. 1989; 30:302-5.

9. Leyva M, Byrd T, Tarwate P. Attitudes towards Cervical Cancer Screening: A study of beliefs among women in Mexico. Californian. 
10. Mettin C, Dodd GD. The American Cancer Society guidelines for the cancer related check-up. An update Int'l J Cancer 1991; 41:279-82.

11. AOCOG Committee Opinion. Routine cancer screening. Int'l J Obstet/Gynaecol.1997; 59:157-61.

12. AACP -Alliance for Cervical Cancer Prevention. Planning and Implementing Cervical Cancer Prevention and Control Programs: A Manual for Managers. Seattle: AACP; 2004.

13. Sania Tanveer Khattak, Imran-ud-din Khattak, Tabassum Naheed, Shehnaz Akhtar, Tanveer Jamal. Detection of abnormal cervical cytology by Pap's Smear. Gomal Journal of Medical Sciences.2006; 4:74-77.

14. Shrivastava M, Shrivastava O P, Jaiswal S S. Pattern of Cervical Smear Cytology in Rural Medical College. Pravara Med Rev 2011; 3(1).

15. Ranabhat SK, Shrestha R, Tiwari M. Analysis of abnormal epithelial lesions in cervical Pap smears in Mid-Western Nepal Journal of Pathology of Nepal.2011; 1: 30 - 33.

16. Bukhari MH, Saba K, Qamar S, Majeed MM, Niazi S. Naeem S. Clinicopathological importance of Papanicolaou smears for the diagnosis of premalignant and malignant lesions of the cervix. J Cytol. 2012 Jan-Mar; 29(1): 20-25.

17. Bal MS, Goyal R, Suri AK, Mohi MK. Detection of abnormal cervical cytology in papaniocoleau smears. Journal of Cytology.2012; 29:45-7.

\begin{tabular}{|c|c|c|c|}
\hline S. No. & Type & No. & $\%$ \\
\hline 1. & Normal smear & 78 & 20.1 \\
\hline 2. & Inadequate smear & 78 & 20.1 \\
\hline 3 & Senile Atopic Changes & 44 & 11.3 \\
\hline 4. & Repeat the smear & 40 & 10.3 \\
\hline 5. & Parasitic Infection & 27 & 7.0 \\
\hline 6. & LSIL (Mild dysplasia) & 104 & 26.8 \\
\hline 7. & HSIL (Moderate \& severe dysplasia) & 15 & 3.9 \\
\hline 8. & Carcinoma cervix & 2 & .5 \\
\hline & Total & 388 & 100.0 \\
\hline
\end{tabular}

\begin{tabular}{|c|c|c|c|c|c|c|c|}
\hline \multirow[b]{2}{*}{ Sl. No } & \multirow[b]{2}{*}{ Types of Lesions } & \multicolumn{6}{|c|}{ Age } \\
\hline & & $\begin{array}{c}\text { 20- } 30 \\
\text { yrs. }\end{array}$ & $\begin{array}{c}\text { 31-40 } \\
\text { yrs. }\end{array}$ & $\begin{array}{c}41-50 \\
\text { yrs. }\end{array}$ & $\begin{array}{c}\text { 51-60 } \\
\text { yrs. }\end{array}$ & $\begin{array}{c}61-70 \\
\text { yrs. }\end{array}$ & $\begin{array}{l}>70 \\
\text { yrs. }\end{array}$ \\
\hline 1 & Normal smear & $\begin{array}{c}22 \\
(28.2 \%)\end{array}$ & $\begin{array}{c}25 \\
(32.1 \%)\end{array}$ & $\begin{array}{c}16 \\
(20.5 \%)\end{array}$ & $\begin{array}{c}9 \\
(11.5 \%)\end{array}$ & $\begin{array}{c}3 \\
(3.8 \%)\end{array}$ & $\begin{array}{c}3 \\
(3.8 \%)\end{array}$ \\
\hline 2 & Inadequate smear & $\begin{array}{c}18 \\
(23.1 \%)\end{array}$ & $\begin{array}{c}23 \\
(29.5 \%)\end{array}$ & $\begin{array}{c}21 \\
(26.9 \%)\end{array}$ & $\begin{array}{c}12 \\
(15.4 \%)\end{array}$ & $\begin{array}{c}2 \\
(2.6 \%) \\
\end{array}$ & $\begin{array}{c}2 \\
(2.6 \%)\end{array}$ \\
\hline 3 & Senile Atopic Changes & $\begin{array}{c}0 \\
(0.0 \%)\end{array}$ & $\begin{array}{c}1 \\
(2.3 \%)\end{array}$ & $\begin{array}{c}13 \\
(29.5 \%)\end{array}$ & $\begin{array}{c}12 \\
(27.3 \%)\end{array}$ & $\begin{array}{c}8 \\
(18.2 \%)\end{array}$ & $\begin{array}{c}10 \\
(22.7 \%)\end{array}$ \\
\hline 4 & Repeat the smear & $\begin{array}{c}10 \\
(25.0 \%)\end{array}$ & $\begin{array}{c}10 \\
(25.0 \%)\end{array}$ & $\begin{array}{c}9 \\
(22.5 \%)\end{array}$ & $\begin{array}{c}5 \\
(12.5 \%)\end{array}$ & $\begin{array}{c}3 \\
(7.5 \%)\end{array}$ & $\begin{array}{c}3 \\
(7.5 \%)\end{array}$ \\
\hline 5 & Parasitic Infection & $\begin{array}{c}11 \\
(40.7 \%)\end{array}$ & $\begin{array}{c}11 \\
(40.7 \%)\end{array}$ & $\begin{array}{c}2 \\
(7.4 \%)\end{array}$ & $\begin{array}{c}2 \\
(7.4 \%)\end{array}$ & $\begin{array}{c}1 \\
(3.7 \%)\end{array}$ & $\begin{array}{c}0 \\
(0.0 \%)\end{array}$ \\
\hline
\end{tabular}


ORIGINAL ARTICLE

\begin{tabular}{|c|c|c|c|c|c|c|c|}
\hline 6 & LSIL (Mild dysplasia) & $\begin{array}{c}9 \\
(8.7 \%)\end{array}$ & $\begin{array}{c}30 \\
(28.8 \%)\end{array}$ & $\begin{array}{c}27 \\
(26.0 \%)\end{array}$ & $\begin{array}{c}23 \\
(22.1 \%)\end{array}$ & $\begin{array}{c}9 \\
(8.7 \%)\end{array}$ & $\begin{array}{c}6 \\
(5.8 \%)\end{array}$ \\
\hline 7 & $\begin{array}{l}\text { HSIL (Moderate } \\
\& \text { severe dysplasia) }\end{array}$ & $\begin{array}{c}0 \\
(0.0 \%)\end{array}$ & $\begin{array}{c}3 \\
(20.0 \%)\end{array}$ & $\begin{array}{c}7 \\
(46.7 \%)\end{array}$ & $\begin{array}{c}1 \\
(6.7 \%)\end{array}$ & $\begin{array}{c}4 \\
(26.7 \%)\end{array}$ & $\begin{array}{c}0 \\
(0.0 \%)\end{array}$ \\
\hline 8 & Carcinoma cervix & $\begin{array}{c}0 \\
(0.0 \%)\end{array}$ & $\begin{array}{c}0 \\
(0.0 \%)\end{array}$ & $\begin{array}{c}1 \\
(50.0 \%)\end{array}$ & $\begin{array}{c}1 \\
(50.0 \%)\end{array}$ & $\begin{array}{c}0 \\
(0.0 \%)\end{array}$ & $\begin{array}{c}0 \\
(0.0 \%)\end{array}$ \\
\hline & Total & $\begin{array}{c}70 \\
(18.0 \%)\end{array}$ & $\begin{array}{c}103 \\
(26.5 \%)\end{array}$ & $96(24.7 \%)$ & $65(16.8 \%)$ & $\begin{array}{c}30 \\
(7.7 \%)\end{array}$ & $\begin{array}{c}24 \\
(6.2 \%)\end{array}$ \\
\hline
\end{tabular}

Chi Sq $=105.396$ p Value $<0.0001$

\section{AUTHORS:}

1. Komal Singh Likhar

2. Ajit Saluja

3. Santosh G. Gupta

4. R. A. Hazari

5. S. K. Likhar

\section{PARTICULARS OF CONTRIBUTORS:}

1. Professor, Department of Pathology, Peoples College of Medical Sciences, Bhopal.

2. Associate Professor, Department of Pathology, Peoples College of Medical Sciences, Bhopal.

3. Professor and HOD, Department of Pathology, Peoples College of Medical Sciences, Bhopal.

4. Professor, Department of Pathology, Peoples College of Medical Sciences, Bhopal.
5. Professor, Department of Community Medicine, Peoples College of Medical Sciences, Bhopal.

\section{NAME ADDRESS EMAIL ID OF THE CORRESPONDING AUTHOR:}

Dr. Komal Singh Likhar,

HIG - 12 B,

Peoples Medical College Campus,

Bhanpur, Bhopal,

Madhya Pradesh - 462037, India.

E-mail: dr.komallikhar@yahoo.com

Date of Submission: 29/01/2014.

Date of Peer Review: 30/01/2014.

Date of Acceptance: 07/02/2014.

Date of Publishing: 19/02/2014. 